\title{
Nerve injury signalling
}

\author{
Namiko Abe and Valeria Cavalli \\ Department of Anatomy and Neurobiology, Washington University in St Louis, 660 S Euclid Avenue, \\ St Louis, MO 63110-1093, USA
}

\section{Summary}

\begin{abstract}
Although neurons within the peripheral nervous system (PNS) have a remarkable ability to repair themselves after injury, neurons within the central nervous system (CNS) do not spontaneously regenerate. This problem has remained recalcitrant despite a century of research on the reaction of axons to injury. The balance between inhibitory cues present in the environment and the intrinsic growth capacity of the injured neuron determine the extent of axonal regeneration following injury. The cell body of an injured neuron must receive accurate and timely information about the site and extent of axonal damage in order to increase its intrinsic growth capacity and successfully regenerate. One of the mechanisms contributing to this process is retrograde transport of injury signals. For example, molecules activated at the injury site convey information to the cell body leading to the expression of regeneration-associated genes and increased growth capacity of the neuron. Here we discuss recent studies that have begun to dissect the injury signalling pathways involved in stimulating the intrinsic growth capacity of injured neurons.
\end{abstract}

\section{Introduction}

The extremely polarized morphology of neurons (i.e. axon length extending for up to one meter) poses challenging problems for intracellular signaling pathways. Information about distant injury, for example, has to be communicated to the cell body to initiate a proper regenerative response. Research on nerve regeneration has classically focused on identifying the inhibitory factors present in the environment, which include the glial scar and molecules such as Nogo and myelin-associated glycoprotein [1]. We know much less about the mechanisms that activate the intrinsic growth capacity of neurons following injury. Upon embryonic to adult transition, the intrinsic neuronal growth activity is repressed to allow for proper synaptic development. Injury to adult peripheral neurons, but not to CNS neurons, reactivate the intrinsic growth capacity and allows regeneration to occur. Primary sensory neurons with cell bodies in the dorsal root ganglion (DRG) provide a useful model system to study the mechanisms that regulate regeneration. DRG neurons are pseudobipolar neurons and possess two axonal branches: a peripheral axon that regenerates when injured and a centrally projecting axon that does not regenerate following injury. Remarkably, injury to the peripheral branch prior to injury to the central branch promotes regeneration of central axons [2,3]. This phenomenon is referred to as the "conditioning lesion" paradigm (Figure 1) and indicates that retrograde injury signals travel from the peripheral injury site back to the cell body to increase the intrinsic growth capacity of the neuron. An increased intrinsic growth state as a result of a preconditioning lesion may enable centrally injured axons to regenerate. A series of elegant studies in the early

Corresponding author: Cavalli, Valeria (cavalli@pcg.wustl.edu).

This is a PDF file of an unedited manuscript that has been accepted for publication. As a service to our customers we are providing this early version of the manuscript. The manuscript will undergo copyediting, typesetting, and review of the resulting proof before it is published in its final citable form. Please note that during the production process errorsmaybe discovered which could affect the content, and all legal disclaimers that apply to the journal pertain. 
1990s in the mollusk Aplysia californica provided evidence for the existence of multiple injury signals functioning in a temporal sequence [4] (Figure 2): injury-induced discharge of axonal potentials, interruption of the normal supply of retrogradely transported target-derived factors (also called negative injury signals) and retrograde injury signals traveling from the injury site back to the cell body (also called positive injury signals).

The retrograde transport of injury signals is one of the essential cellular mechanisms leading to regeneration. Coordination between several injury signaling pathways is necessary to regulate the appropriate genes to promote neuronal survival and increase the intrinsic growth state of injured neurons. In this review, we discuss recent studies that departed from the traditional focus on extrinsic factors and uncovered distinct signalling mechanisms leading to the enhanced intrinsic growth capacity of peripheral neurons following injury.

\section{Axonal injury signalling}

\section{Positive injury signals}

The positive injury signals identified thus far cover a broad array of functionally distinct proteins that include members of the mitogen-activated protein kinase family (MAPK), cytokines and their downstream transcription factors, as well as locally-translated importin, a main regulator of nuclear import and export.

Axonal transport of several kinases was initially suggested to play a role in relaying information from the nerve terminal to the cell body [5]. It is now known that axonal injury induces local activation and retrograde transport of several MAPKs, including Erk [6,7], the c-Jun Nterminal kinase (JNK) [8,9] and the protein kinase G [10]. These studies strongly suggest that activation of kinases, in particular JNK and Erk and their interaction with the dynein/dynactin retrograde molecular motors is required for regeneration [6,8]. Transport of such injury signal is complicated by the fact that many kinases including JNK and Erk are activated by reversible phosphorylation and without proper protection this signal may not persist. A key question is then how to prevent deactivation of the signal during the long journey to the cell body. One elegant solution is to protect the signal with scaffolding proteins. For example, it has been recently shown that the intermediate filament vimentin interacts with phosphorylated Erk1 to protect it from dephosphorylation by calcium-dependent steric hindrance [11]. Another mechanism proposed to protect dephosphorylation is storage within intraluminal vesicles of multivesicular bodies [12]. Indeed, kinases such as JNK can hitchhike on axonal vesicles [8] and intraluminal vesicles are not always destined to lysosomes for degradation; they can also fuse back with the limiting membrane of late endosomes [13]. This process is hijacked by several toxins and viruses to reach the cell body and could similarly be exploited by signaling proteins. Combined with a protection mechanism against phosphatases during transport, activation and retrograde transport of MAPKs might play an important role in regeneration. The upstream signalling cascade leading to MAPK activation in the axon remains yet to be established.

In addition to MAPK, axonal injury activates several transcription factors through the local release of cytokines. These include the gp130 cytokines leukemia inhibitory factor (LIF), interleukein-6 (IL-6), and ciliary neurotrophic factor (CNTF). LIF and IL-6 are required for the increased growth state of DRG neurons following peripheral injury through activation of downstream genes such as GAP43 [14,15], although Cao and colleagues [16] reported that IL-6 knockout animals do not show defects in nerve regeneration. Upregulation of IL-6 in DRG cell bodies themselves following injury [16-18] raises the possibility of paracrine or autocrine action of IL-6, which may amplify a cytokine-induced retrograde signal. The gp130 cytokines signal through a common receptor, gp 130, and the JAK-STAT pathway, which leads to STAT3 phosphorylation and translocation into the nucleus [19]. Although retrograde transport of 
locally activated STAT3 has been suggested [20,21], in vitro studies using compartmentalized cultures suggest a signaling endosome model in which the gp130/JAK complex is endocytosed and retrogradely transported to activate STAT3 in the cell body [22]. Interestingly, STAT3 activation through the Jak2 signalling pathway occurs in DRG neurons cell body after peripheral, but not central lesion [23,24], strongly supporting a role for STAT3 in neuronal regeneration. While STAT3 signalling promotes axonal re-growth, in vitro studies showed that suppressor of cytokine signaling (SOCS3) inhibits STAT3 [25] and SOCS3 levels are increased by peripheral injury $[25,26]$. While the influence of endogenous SOCS3 on axonal growth in peripheral neurons may be limited, SOCS3 may contribute to the lack of regeneration in CNS neurons [25]. The pathways leading to STAT3 activation are partially understood but the downstream targets of the cytokine-STAT3 signalling remains to be clearly defined.

Work over the past ten years has confirmed that axons have the capacity to locally synthesize proteins [27]. Axonal mRNA translation plays a role in axonal growth during development [27] and mature neurons use axonal mRNA translation to transfer injury signals to the nucleus of injured neurons. Following peripheral nerve injury, de novo synthesis of importin-beta [7] and vimentin [6] leads to the formation of an importin-activated Erk-vimentin complex that recruits the retrograde motor dynein, linking the nuclear import machinery to retrograde injury signaling [6]. Since a surprisingly large population of mRNAs localizes to sensory axons [28], future studies will reveal the possible role for other de novo synthesized proteins in injury signaling.

The positive injury signals identified so far share one common requirement, microtubuledependent retrograde transport. Future studies will likely identify new molecules involved in injury signaling. It is tempting to speculate that the combination of several positive injury signals might serve as an indicator of the extent and nature of damage.

\section{Negative injury signals}

Although loss of negative cues represents another important mechanism to sense injury, surprisingly little is known about this type of signalling. Once a neuron is connected with its target, target-derived signals must repress the intrinsic neuronal growth activity to allow for proper synaptic development. This repression has to be relieved to allow regeneration to occur. Although neurotrophins represent the ideal candidates, evidence for their role as negative signals following injury have not yet been established. One recently identified negative injury signal is the TGF beta/SMAD2/SMAD3 pathway (Zhigang He). SMAD2 is down-regulated following peripheral nerve injury, indicating that SMAD2-dependent gene transcription may restrict the axonal growth ability in healthy neurons and injury may relieve this inhibition. Whether SMAD2/SMAD3 contributes to the decreased regenerative ability of adult CNS neurons remains to be determined. The transcription factor ATF-2 is also rapidly suppressed in neurons following injury [29]. Similarly to SMAD2, ATF2-dependent gene transcription may repress neuronal growth capacity. Future studies are needed to explore the role of negative injury signals in axonal regeneration.

\section{Electrical Activity}

Recent data suggest an important role of neural activity in regeneration. The transection of axons initiates a large depolarizing voltage discharge that travels back to the soma and triggers vigorous spiking activity and sustained depolarization [30]. This extensive electrical activity produces a strong calcium influx in both the axon and the soma. Propagation of this response requires the activation of voltage-gated sodium channels and is necessary for regeneration, since axotomy in the presence of tetrodotoxin reduces the regenerative process [30]. Calcium influx is also necessary for regeneration in vitro and is likely to act through protein kinases such as ERK or PKA [31]. In vivo studies showed that electrical stimulation accelerates motor 
[32] and sensory [33] axon outgrowth and increases intracellular cAMP levels in DRG neurons as effectively as the conditioning lesion [33]. However, electrical stimulation did not recapitulate all characteristics of axonal outgrowth, indicating that cAMP alone is not sufficient to trigger a complete regenerative response [33]. In marked contrast, electrical stimulation of CNS axons does not promote regeneration, even when provided a permissive growth environment through a peripheral nerve graft [34]. Electrical activity thus may play an important role as an early injury signal in the PNS, but might be insufficient to initiate regeneration of CNS neurons.

\section{Signalling mechanisms in CNS axons}

Induction of retrograde injury signals has so far been demonstrated in peripheral neurons. Recent studies in CNS neurons of the retina have unraveled the existence of parallel mechanisms between CNS and PNS neurons and demonstrated that the growth capacity of CNS neurons can be enhanced. While retinal ganglion cells (RGCs) normally fail to regenerate their injured axons, lens injury activates macrophages and stimulates regeneration of RGCs [35] in a process that resemble the conditioning injury in DRG neurons. Soluble factors released by activated macrophages, such as oncomodulin, are sufficient to promote RGC regeneration through a $\mathrm{Ca} 2+/$ calmodulin dependent pathway [35]. While oncomodulin promotes neurite outgrowth in cultured central and peripheral neurons [36], its role in sensory nerve regeneration has yet to be explored in vivo. Lens injury also induces upregulation of CNTF in retinal astrocytes, a process that is independent of macrophages, and leads to STAT3 activation in RGCs [37,38]. The cytokine-mediated activation of STAT3 is a central injury signaling mechanism in PNS neurons, suggesting another possible parallel between the responses of CNS and PNS neurons to injury. To elucidate molecular factors responsible for the poor regenerative capacity of the CNS neurons, it will be important to determine whether CNS neurons lack the ability to activate or transport injury signals, are unable to relieve the growth inhibition brought about during their maturation or are less responsive to cytokines and other injury induced stimuli.

\section{Somatic injury signalling}

\section{Role of cAMP}

Elevation of cAMP levels in the soma following axonal injury to peripheral neurons contributes to initiation of axonal re-growth (for a recent review, see [39]). cAMP not only increases the growth capacity of injured neurons but also partly relieves CNS myelin inhibition. The increase in cAMP levels appears to be transient and initiates a series of signaling pathways involving PKA [40]. The effects of cAMP are transcription dependent [41] and require the transcription factor cAMP response element binding protein (CREB) [42]. Interestingly, CREB mRNA is present in developing axons and CREB translation and retrograde transport is triggered by the nerve growth factor (NGF) [43]. Whether CREB translation may play a role in injury signaling in adult neurons remains to be determined. Downstream targets of cAMP signaling include Arginase1, which mediates synthesis of polyamines [44], neuropeptide Y, CREM (cAMP response element modulator), VGF (nerve growth factor-inducible growth factor) and IL-6 $[16,18]$. Some of these genes were also identified in studies comparing the pattern of gene expression at different times after sciatic nerve transection [26,45], revealing a temporal hierarchy of gene activation following injury. Although cAMP analogs fail to activate the intrinsic growth state of RGCs [46] they potentiate the effect of lens injury [38], indicating that multiple pathways act in parallel to stimulate RGCs regeneration. Although a direct link between retrograde signalling in axons and elevation of cAMP in cell body of injured neurons is still lacking, these results strongly suggest that the intrinsic growth capacity of the CNS neurons can be enhanced under appropriate conditions. 


\section{Transcription factors}

Initiation of a regeneration program requires that retrograde signals from the injury site alter transcription of multiple genes [41]. Members of the immediate-early genes family, including c-Jun and JunD [47,48], as well as members of the constitutive transcription factors CREB, STAT3, SOX11 and ATF3 $[23,42,49,50]$ are elevated and in some cases also activated in DRG cell bodies after peripheral injury. The activation of c-Jun in the cell body is essential for the initiation of transcriptional changes required for successful axonal regeneration. Some of the identified c-Jun-dependent genes include integrin $\alpha 7 \beta 1$, CD44 and galanin [51]. Deletion of $c-J u n$ in the nervous system, while causing little effect on axonal growth during development, leads to a marked defect in regeneration upon nerve transection [51]. The importance of c-Jun for regeneration also come from the observation that c-Jun activation in DRGs is drastically greater following peripheral vs. central branch axotomy [52] and c-Jun activation persists until successful target re-innervation has been achieved [53,54]. The time course of c-Jun induction depends on the distance between the injury site and the cell body [53], suggesting that JNK activation in the axon may lead to c-Jun expression in the cell body $[8,9]$. Similarly to c-Jun, ATF3 and STAT3 are induced in DRG neurons after peripheral, but not central injury [23, 55]. Overexpression of ATF-3 in cultured neurons enhances neurite outgrowth [55] and transgenic expression of ATF3 can partially recapitulate a conditioning injury [56]. Conditional gene disruption of STAT3 indicates that this gene may contribute to the survival of motor neurons after peripheral nerve lesion through activation of motor neuron survival factors such as Reg-2 and Bcl-xl [57], but a direct role on nerve regeneration per se has not been demonstrated. In vitro studies show that another transcription factor Sox 11 is expressed at high levels in developing and regenerating sensory neurons and regulates neurite outgrowth and cell survival [58]. While the identity of the genes activated by injury is being unraveled, the overall sequence and coordination of transcriptional events that initiate and sustain a regeneration program awaits further studies.

\section{Neurotrophins}

Neurotrophic signaling is mostly known to play a role in neuronal survival during development. The function of neurotrophins has been recently extended to other aspects of neuronal function, including regeneration [59]. Upregulation of the glial-derived neurotophic factor GDNF and one of its receptors GFR $\alpha 1$ in injured nerves suggest that GDNF provides neurotrophic support for injured DRG neurons [60]. GDNF delivery directly to DRG cell bodies facilitates the conditioning injury-induced growth promoting effect [61]. Although GDNF and GFR $\alpha 1$ are retrogradely transported in peripheral axons [62], a role of GDNF in injury signaling has not yet been examined. Fibroblast growth factor-2 (FGF-2) is another neurotrophic factor contributing to nerve regeneration [63]. FGF-2 is upregulated following injury both at the lesion site and in the cell bodies of peripheral nerves and transgenic mice over-expressing FGF2 show a greater increase in the number of regenerating axons after sciatic nerve transection [64]. The presence of neurotrophin signaling in injured nerve emphasizes the signaling crosstalk that is required to promote neuronal survival and regeneration.

\section{Conclusions}

A single signaling pathway is unlikely to fully mediate nerve regeneration. Several classes of injury signals may coexist to ensure precise information on the nature of the damage and its distance from the cell body. It is tempting to speculate that the difference in time between the arrival at the soma of the back propagating axonal depolarization - the first injury signal, and the later arrival of a positive injury signal might serve as an indicator of the distance of the injury site from the cell body. However, a clear link between the arrival of injury signals and specific gene activation is still missing. Ultimately, a direct comparison between injury signaling mechanisms in CNS and PNS neurons might shed light on the poor regenerative 
capacity of CNS neurons. This knowledge will be essential to our understanding and ultimately treatment of many debilitating CNS disorders, since in addition to traumatic axonal damage resulting from spinal cord injury or stroke, axonal damage can also occur in many neurodegenerative diseases in which axonal pathologies interrupt the cell body/synapse connection.

\section{Acknowledgments}

We thank Vitaly Klyachko and Erik Herzog for critical reading of the manuscript. This work was supported by NIH (NS060709) to Valeria Cavalli.

\section{References and recommended reading}

Paper of particular interests, published within the annual period of review, have been highlighted as:

* of special interest

** of outstanding interest

1. Schwab ME. Nogo and axon regeneration. Curr Opin Neurobiol 2004;14:118-124. [PubMed: 15018947]

2. Richardson PM, Issa VM. Peripheral injury enhances central regeneration of primary sensory neurones. Nature 1984;309:791-793. [PubMed: 6204205]

3. Neumann S, Woolf CJ. Regeneration of dorsal column fibers into and beyond the lesion site following adult spinal cord injury. Neuron 1999;23:83-91. [PubMed: 10402195]

4. Ambron RT, Walters ET. Priming events and retrograde injury signals. A new perspective on the cellular and molecular biology of nerve regeneration. Mol Neurobiol 1996;13:61-79. [PubMed: 8892336]

5. Johanson SO, Crouch MF, Hendry IA. Retrograde axonal transport of signal transduction proteins in rat sciatic nerve. Brain Res 1995;690:55-63. [PubMed: 7496807]

6. Perlson E, Hanz S, Ben-Yaakov K, Segal-Ruder Y, Seger R, Fainzilber M. Vimentin-dependent spatial translocation of an activated MAP kinase in injured nerve. Neuron 2005;45:715-726. [PubMed: 15748847] ** The authors show that the intermediate filament vimentin is locally translated in sciatic nerve axoplasm following injury, and that the newly synthesized vimentin links activated MAP kinases Erk1 and Erk2 to the dynein motor retrograde motor complex. Importantly, they provide functional evidence for the role of vimentin in injury signaling by showing that neurite outgrowth in DRGs following a nerve conditioning lesion is inhibited in vimentin null mice. They further find that the activation of Elk1, a downstream target of activated Erks, is impaired in these mice, suggesting that vimentin is necessary for retrograde transport of active Erk following injury.

7. Hanz S, Perlson E, Willis D, Zheng JQ, Massarwa R, Huerta JJ, Koltzenburg M, Kohler M, van-Minnen J, Twiss JL, et al. Axoplasmic importins enable retrograde injury signaling in lesioned nerve. Neuron 2003;40:1095-1104. [PubMed: 14687545]

8. Cavalli V, Kujala P, Klumperman J, Goldstein LS. Sunday Driver links axonal transport to damage signaling. J Cell Biol 2005;168:775-787. [PubMed: 15738268] ** The authors use biochemical, immunofluorescence and EM techniques in the mouse sciatic nerve to show that syd mediates the axonal transport of vesicles and interact with both the anterograde motor kinesin and the retrograde motor complex dynein/dynactin. In response to sciatic nerve damage, JNK is locally activated within axons and syd preferentially interacts with the retrograde motor dynein/dynactin, resulting in increased syd and activated JNK retrograde transport.

9. Lindwall C, Kanje M. Retrograde axonal transport of JNK signaling molecules influence injury induced nuclear changes in p-c-Jun and ATF3 in adult rat sensory neurons. Mol Cell Neurosci 2005;29:269_ 282. [PubMed: 15911351] 
10. Sung YJ, Chiu DT, Ambron RT. Activation and retrograde transport of protein kinase G in rat nociceptive neurons after nerve injury and inflammation. Neuroscience 2006;141:697-709. [PubMed: 16730916]

11. Perlson E, Michaelevski I, Kowalsman N, Ben-Yaakov K, Shaked M, Seger R, Eisenstein M, Fainzilber M. Vimentin binding to phosphorylated erk sterically hinders enzymatic dephosphorylation of the kinase. J Mol Biol 2006;364:938-944. [PubMed: 17046786] ** This study is the first to show how scaffolding proteins protect activated kinases from dephosphorylation during retrograde transport. Through a series of elegant biochemical and molecular modeling experiments, the authors show that vimentin protects the phosphorylation site of Erk by calcium-dependent steric hindrance.

12. Weible MW 2nd, Hendry IA. What is the importance of multivesicular bodies in retrograde axonal transport in vivo? J Neurobiol 2004;58:230-243. [PubMed: 14704955]

13. van der Goot FG, Gruenberg J. Intra-endosomal membrane traffic. Trends Cell Biol 2006;16:514521. [PubMed: 16949287]

14. Cafferty WB, Gardiner NJ, Gavazzi I, Powell J, McMahon SB, Heath JK, Munson J, Cohen J, Thompson SW. Leukemia inhibitory factor determines the growth status of injured adult sensory neurons. J Neurosci 2001;21:7161-7170. [PubMed: 11549727]

15. Cafferty WB, Gardiner NJ, Das P, Qiu J, McMahon SB, Thompson SW. Conditioning injury-induced spinal axon regeneration fails in interleukin-6 knock-out mice. J Neurosci 2004;24:4432-4443. [PubMed: 15128857]

16. Cao Z, Gao Y, Bryson JB, Hou J, Chaudhry N, Siddiq M, Martinez J, Spencer T, Carmel J, Hart RB, et al. The cytokine interleukin- 6 is sufficient but not necessary to mimic the peripheral conditioning lesion effect on axonal growth. J Neurosci 2006;26:5565-5573. [PubMed: 16707807] * This study shows that the cytokine interleukin-6 is expressed in DRGs following peripheral conditioning injury and that IL-6 is sufficient to mimic the conditioning effect on DRG neurite outgrowth. Contrary to the findings of Cafferty et al 2004, the authors of this study show that IL-6 is not necessary for the enhancement of nerve growth state by a peripheral conditioning injury.

17. Murphy PG, Grondin J, Altares M, Richardson PM. Induction of interleukin-6 in axotomized sensory neurons. J Neurosci 1995;15:5130-5138. [PubMed: 7623140]

18. Wu D, Zhang Y, Bo X, Huang W, Xiao F, Zhang X, Miao T, Magoulas C, Subang MC, Richardson PM. Actions of neuropoietic cytokines and cyclic AMP in regenerative conditioning of rat primary sensory neurons. Exp Neurol 2007;204:66-76. [PubMed: 17112514] ** This report links the beneficial effects of cAMP activity on axonal regeneration to cytokine signaling. The authors show that addition of cAMP into DRGs induces the expression of neuropoietic cytokines IL- 6 and LIF, which has been shown to be positive regulators of nerve regeneration.

19. Heinrich PC, Behrmann I, Haan S, Hermanns HM, Muller-Newen G, Schaper F. Principles of interleukin (IL)-6-type cytokine signalling and its regulation. Biochem J 2003;374:1-20. [PubMed: 12773095]

20. Sheu JY, Kulhanek DJ, Eckenstein FP. Differential patterns of ERK and STAT3 phosphorylation after sciatic nerve transection in the rat. Exp Neurol 2000;166:392-402. [PubMed: 11085904]

21. Lee N, Neitzel KL, Devlin BK, MacLennan AJ. STAT3 phosphorylation in injured axons before sensory and motor neuron nuclei: potential role for STAT3 as a retrograde signaling transcription factor. J Comp Neurol 2004;474:535-545. [PubMed: 15174071]

22. O'Brien JJ, Nathanson NM. Retrograde activation of STAT3 by leukemia inhibitory factor in sympathetic neurons. J Neurochem 2007;103:288-302. [PubMed: 17608645] ** The authors of this study use compartmentalized cultures of sympathetic neurons to investigate the mechanism of LIFmediated retrograde signaling. Their results support a signaling endosome model in which the LIF/ gp130/Jak complex is internalized at the distal axon and retrogradely transported to mediate STAT3 activation in the cell body.

23. Schwaiger FW, Hager G, Schmitt AB, Horvat A, Hager G, Streif R, Spitzer C, Gamal S, Breuer S, Brook GA, et al. Peripheral but not central axotomy induces changes in Janus kinases (JAK) and signal transducers and activators of transcription (STAT). Eur J Neurosci 2000;12:1165-1176. [PubMed: 10762348]

24. Qiu J, Cafferty WB, McMahon SB, Thompson SW. Conditioning injury-induced spinal axon regeneration requires signal transducer and activator of transcription 3 activation. J Neurosci 
2005;25:1645-1653. [PubMed: 15716400]* This study finds that peripheral, but not central axotomy induces STAT3 activation in DRG neurons. By pharmacological inhibition of STAT3 activation in sciatic nerve in vivo, the authors show that STAT3 activation is required for peripheral nerve regeneration

25. Miao T, Wu D, Zhang Y, Bo X, Subang MC, Wang P, Richardson PM. Suppressor of cytokine signaling-3 suppresses the ability of activated signal transducer and activator of transcription-3 to stimulate neurite growth in rat primary sensory neurons. J Neurosci 2006;26:9512-9519. [PubMed: 16971535] * This study identifies SOC3 as an inhibitor of STAT3 activation, and a negative regulator of neurite outgrowth in vitro. This observation raises the possibility that SOC3 may contributes to the inability of CNS neurons to regenerate following injury.

26. Nilsson A, Moller K, Dahlin L, Lundborg G, Kanje M. Early changes in gene expression in the dorsal root ganglia after transection of the sciatic nerve; effects of amphiregulin and PAI-1 on regeneration. Brain Res Mol Brain Res 2005;136:65-74. [PubMed: 15893588]

27. Twiss JL, van Minnen J. New insights into neuronal regeneration: the role of axonal protein synthesis in pathfinding and axonal extension. J Neurotrauma 2006;23:295-308. [PubMed: 16629617]

28. Willis D, Li KW, Zheng JQ, Chang JH, Smit A, Kelly T, Merianda TT, Sylvester J, van Minnen J, Twiss JL. Differential transport and local translation of cytoskeletal, injury-response, and neurodegeneration protein mRNAs in axons. J Neurosci 2005;25:778-791. [PubMed: 15673657]

29. Martin-Villalba A, Winter C, Brecht S, Buschmann T, Zimmermann M, Herdegen T. Rapid and longlasting suppression of the ATF-2 transcription factor is a common response to neuronal injury. Brain Res Mol Brain Res 1998;62:158-166. [PubMed: 9813301]

30. Mandolesi G, Madeddu F, Bozzi Y, Maffei L, Ratto GM. Acute physiological response of mammalian central neurons to axotomy: ionic regulation and electrical activity. Faseb J 2004;18:1934-1936. [PubMed: 15451889]

31. Chierzi S, Ratto GM, Verma P, Fawcett JW. The ability of axons to regenerate their growth cones depends on axonal type and age, and is regulated by calcium, cAMP and ERK. Eur J Neurosci 2005;21:2051-2062. [PubMed: 15869501]

32. Al-Majed AA, Tam SL, Gordon T. Electrical stimulation accelerates and enhances expression of regeneration-associated genes in regenerating rat femoral motoneurons. Cell Mol Neurobiol 2004;24:379-402. [PubMed: 15206821]

33. Udina E, Furey M, Busch S, Silver J, Gordon T, Fouad K. Electrical stimulation of intact peripheral sensory axons in rats promotes outgrowth of their central projections. Exp Neurol 2008;210:238247. [PubMed: 18164293] * The authors demonstrate that electrical stimulation in the intact sciatic nerve mimics the conditioning-injury effect on DRG axon outgrowth, and that this effect of electrical stimulation is correlated with increased cAMP activity.

34. Harvey PJ, Grochmal J, Tetzlaff W, Gordon T, Bennett DJ. An investigation into the potential for activity-dependent regeneration of the rubrospinal tract after spinal cord injury. Eur J Neurosci 2005;22:3025-3035. [PubMed: 16367769]

35. Yin Y, Cui Q, Li Y, Irwin N, Fischer D, Harvey AR, Benowitz LI. Macrophage-derived factors stimulate optic nerve regeneration. J Neurosci 2003;23:2284-2293. [PubMed: 12657687]

36. Yin Y, Henzl MT, Lorber B, Nakazawa T, Thomas TT, Jiang F, Langer R, Benowitz LI. Oncomodulin is a macrophage-derived signal for axon regeneration in retinal ganglion cells. Nat Neurosci 2006;9:843-852. [PubMed: 16699509] ** This study identified oncomodulin as a macrophagedderived secreted factor that promotes the regeneration of injured retinal ganglion cells. The study further shows that oncomodulin can stimulate neurite outgrowth in cultured DRG neurons.

37. Muller A, Hauk TG, Fischer D. Astrocyte-derived CNTF switches mature RGCs to a regenerative state following inflammatory stimulation. Brain 2007;130:3308-3320. [PubMed: 17971355]

38. Park K, Luo JM, Hisheh S, Harvey AR, Cui Q. Cellular mechanisms associated with spontaneous and ciliary neurotrophic factor-cAMP-induced survival and axonal regeneration of adult retinal ganglion cells. J Neurosci 2004;24:10806-10815. [PubMed: 15574731]

39. Hannila SS, Filbin MT. The role of cyclic AMP signaling in promoting axonal regeneration after spinal cord injury. Exp Neurol 2008;209:321-332. [PubMed: 17720160]

40. Qiu J, Cai D, Dai H, McAtee M, Hoffman PN, Bregman BS, Filbin MT. Spinal axon regeneration induced by elevation of cyclic AMP. Neuron 2002;34:895-903. [PubMed: 12086638] 
41. Smith DS, Skene JH. A transcription-dependent switch controls competence of adult neurons for distinct modes of axon growth. J Neurosci 1997;17:646-658. [PubMed: 8987787]

42. Gao Y, Deng K, Hou J, Bryson JB, Barco A, Nikulina E, Spencer T, Mellado W, Kandel ER, Filbin MT. Activated CREB is sufficient to overcome inhibitors in myelin and promote spinal axon regeneration in vivo. Neuron 2004;44:609-621. [PubMed: 15541310]

43. Cox LJ, Hengst U, Gurskaya NG, Lukyanov KA, Jaffrey SR. Intra-axonal translation and retrograde trafficking of CREB promotes neuronal survival. Nat Cell Biol 2008;10:149-159. [PubMed: $18193038]$ * The authors of this study show that axonal protein synthesis is required for NGFdependent cell survival in developing sensory neurons. They further show that the transcription factor CREB is locally translated by NGF signaling and that newly synthesized CREB is retrogradely transported to the cell body.

44. Cai D, Deng K, Mellado W, Lee J, Ratan RR, Filbin MT. Arginase I and polyamines act downstream from cyclic AMP in overcoming inhibition of axonal growth MAG and myelin in vitro. Neuron 2002;35:711-719. [PubMed: 12194870]

45. Costigan M, Befort K, Karchewski L, Griffin RS, D'Urso D, Allchorne A, Sitarski J, Mannion JW, Pratt RE, Woolf CJ. Replicate high-density rat genome oligonucleotide microarrays reveal hundreds of regulated genes in the dorsal root ganglion after peripheral nerve injury. BMC Neurosci 2002;3:16. [PubMed: 12401135]

46. Goldberg JL, Klassen MP, Hua Y, Barres BA. Amacrine-signaled loss of intrinsic axon growth ability by retinal ganglion cells. Science 2002;296:1860-1864. [PubMed: 12052959]

47. Leah JD, Herdegen T, Bravo R. Selective expression of Jun proteins following axotomy and axonal transport block in peripheral nerves in the rat: evidence for a role in the regeneration process. Brain Res 1991;566:198-207. [PubMed: 1726060]

48. Jenkins R, Hunt SP. Long-term increase in the levels of c-jun mRNA and jun protein-like immunoreactivity in motor and sensory neurons following axon damage. Neurosci Lett 1991;129:107-110. [PubMed: 1922958]

49. Tanabe K, Bonilla I, Winkles JA, Strittmatter SM. Fibroblast growth factor-inducible-14 is induced in axotomized neurons and promotes neurite outgrowth. J Neurosci 2003;23:9675-9686. [PubMed: 14573547]

50. Tsujino H, Kondo E, Fukuoka T, Dai Y, Tokunaga A, Miki K, Yonenobu K, Ochi T, Noguchi K. Activating transcription factor 3 (ATF3) induction by axotomy in sensory and motoneurons: A novel neuronal marker of nerve injury. Mol Cell Neurosci 2000;15:170-182. [PubMed: 10673325]

51. Raivich G, Bohatschek M, Da Costa C, Iwata O, Galiano M, Hristova M, Nateri AS, Makwana M, Riera-Sans L, Wolfer DP, et al. The AP-1 transcription factor c-Jun is required for efficient axonal regeneration. Neuron 2004;43:57-67. [PubMed: 15233917]

52. Broude E, McAtee M, Kelley MS, Bregman BS. c-Jun expression in adult rat dorsal root ganglion neurons: differential response after central or peripheral axotomy. Exp Neurol 1997;148:367-377. [PubMed: 9398479]

53. Kenney AM, Kocsis JD. Peripheral axotomy induces long-term c-Jun amino-terminal kinase-1 activation and activator protein-1 binding activity by c-Jun and junD in adult rat dorsal root ganglia In vivo. J Neurosci 1998;18:1318-1328. [PubMed: 9454841]

54. Herdegen T, Claret FX, Kallunki T, Martin-Villalba A, Winter C, Hunter T, Karin M. Lasting Nterminal phosphorylation of c-Jun and activation of c-Jun N-terminal kinases after neuronal injury. J Neurosci 1998;18:5124-5135. [PubMed: 9651196]

55. Seijffers R, Allchorne AJ, Woolf CJ. The transcription factor ATF-3 promotes neurite outgrowth. Mol Cell Neurosci 2006;32:143-154. [PubMed: 16713293]

56. Seijffers R, Mills CD, Woolf CJ. ATF3 increases the intrinsic growth state of DRG neurons to enhance peripheral nerve regeneration. J Neurosci 2007;27:7911-7920. [PubMed: 17652582] * Using transgenic mice that constitutively express ATF-3 in neurons, the authors of this study show that ATF-3 increases axonal growth capacity following a sciatic nerve conditioning injury.

57. Schweizer U, Gunnersen J, Karch C, Wiese S, Holtmann B, Takeda K, Akira S, Sendtner M. Conditional gene ablation of Stat3 reveals differential signaling requirements for survival of motoneurons during development and after nerve injury in the adult. J Cell Biol 2002;156:287-297. [PubMed: 11807093] 
58. Jankowski MP, Cornuet PK, McIlwrath S, Koerber HR, Albers KM. SRY-box containing gene 11 (Sox11) transcription factor is required for neuron survival and neurite growth. Neuroscience 2006;143:501-514. [PubMed: 17055661] This study provides extensive in vitro evidence for the role of Sox 11 in the regulation of neuronal survival and neurite outgrowth in sensory neurons. DNA microarray analysis from neuroblastoma cells shows that Sox 11 regulates the expression of apoptosis-related genes.

59. Cui Q. Actions of neurotrophic factors and their signaling pathways in neuronal survival and axonal regeneration. Mol Neurobiol 2006;33:155-179. [PubMed: 16603794]

60. Hoke A, Cheng C, Zochodne DW. Expression of glial cell line-derived neurotrophic factor family of growth factors in peripheral nerve injury in rats. Neuroreport 2000;11:1651-1654. [PubMed: 10852218]

61. Mills CD, Allchorne AJ, Griffin RS, Woolf CJ, Costigan M. GDNF selectively promotes regeneration of injury-primed sensory neurons in the lesioned spinal cord. Mol Cell Neurosci 2007;36:185-194. [PubMed: 17702601] * This study explores the role of GDNF in peripheral nerve regeneration. The authors show that peripheral nerve injury upregulates components of GDNF signaling, and that exogenous GDNF treatment enhances the effect of conditioning-injury on neurite outgrowth.

62. Coulpier M, Ibanez CF. Retrograde propagation of GDNF-mediated signals in sympathetic neurons. Mol Cell Neurosci 2004;27:132-139. [PubMed: 15485769]

63. Grothe $\mathrm{C}$, Nikkhah $\mathrm{G}$. The role of basic fibroblast growth factor in peripheral nerve regeneration. Anat Embryol (Berl) 2001;204:171-177. [PubMed: 11681796]

64. Jungnickel J, Haase K, Konitzer J, Timmer M, Grothe C. Faster nerve regeneration after sciatic nerve injury in mice over-expressing basic fibroblast growth factor. J Neurobiol 2006;66:940-948. [PubMed: 16758491] ** This carefully conducted study uses transgenic mice overexpressing FGF-2 to address the contribution of FGF-2 to nerve regeneration. The authors find that FGF-2 overexpression facilitates peripheral nerve regeneration following crush injury by regulating axonal growth, as well as Schwann cell proliferation and axonal myelination. 


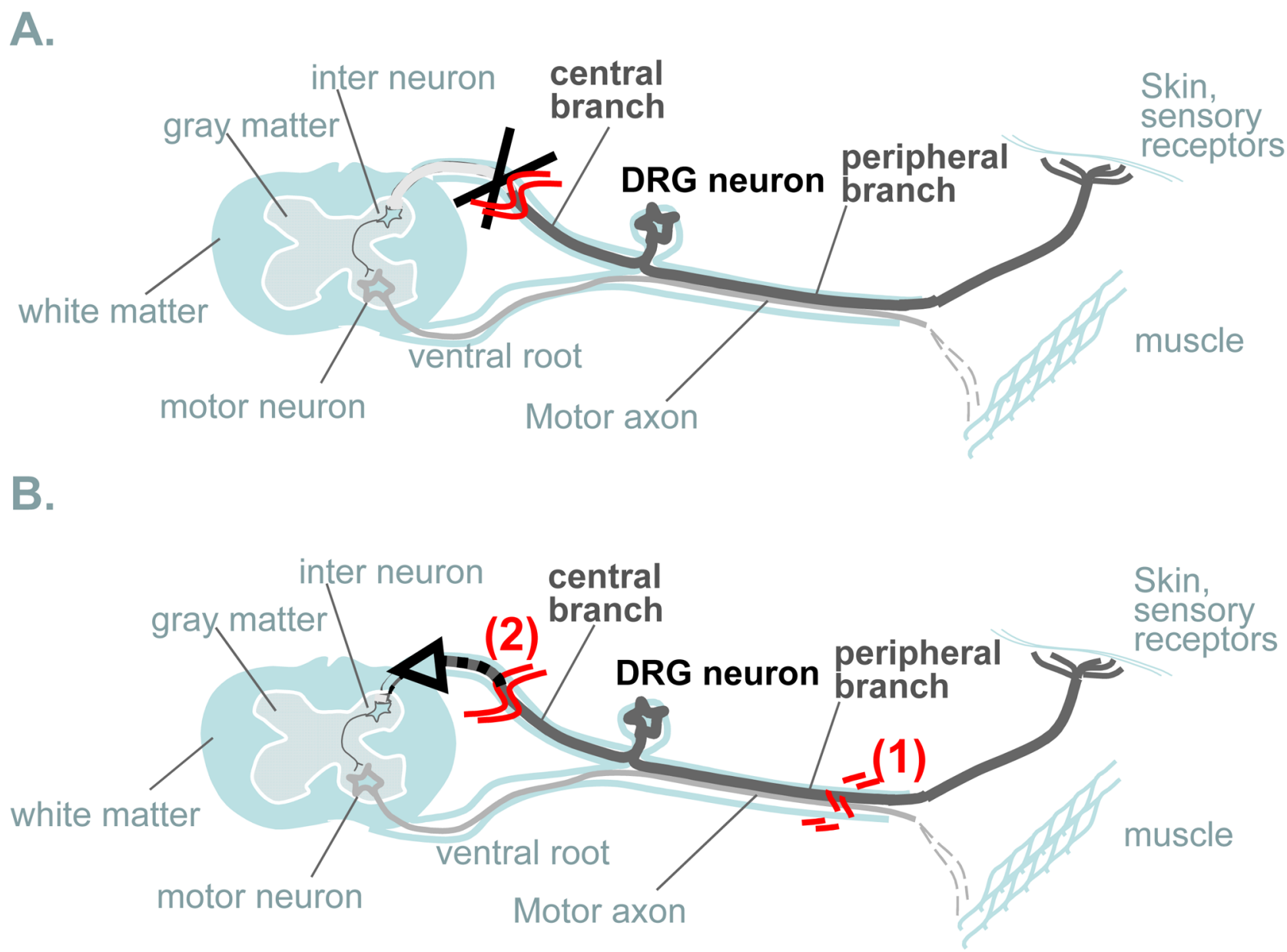

Figure 1. Signalling mechanisms

The cell body of injured neurons must receive accurate and timely information on the site and extent of axonal damage in order to orchestrate an appropriate response leading to successful regeneration. Pioneering work from the laboratories of Ambron and Walters have led to the notion that three distinct signaling mechanisms may act in complementary and synergistic roles: (1) injury-induced discharge of axonal potentials, (2) interruption of the normal supply of retrogradely transported trophic factors or negative regulators of neuronal growth from the target and (3) retrograde transport of activated proteins emanating at the injury site, termed positive injury signals. 


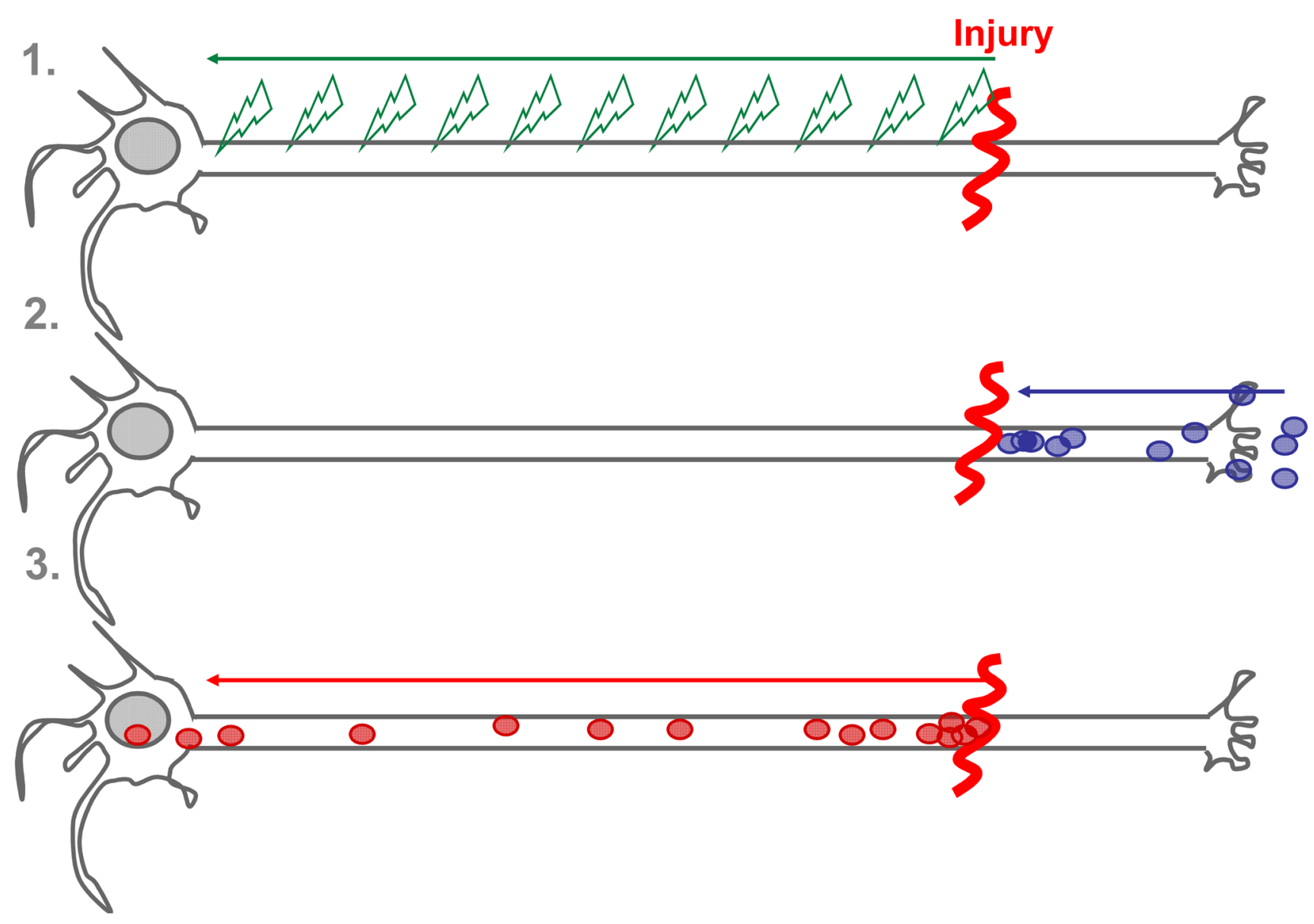

Figure 2. Conditioning injury paradigm

Primary sensory neurons within dorsal root ganglia (DRG) are particularly useful to study axonal regeneration. DRG neurons are unique in having two axonal branches; a long sensory CNS branch ascends the dorsal column in the spinal cord and a second branch projects through a peripheral nerve. Sensory axons in the adult spinal cord do not regenerate after injury (A), while peripheral injury result in a robust regenerative response. Regeneration of the central branch can be greatly enhanced by a prior injury to the peripheral branch, referred to as a "conditioning injury" (B). The conditioning injury suggests that distinct signaling mechanisms regulate responses to central vs. peripheral injury in DRG neurons and may contribute to their different abilities to axonal regrowth. 


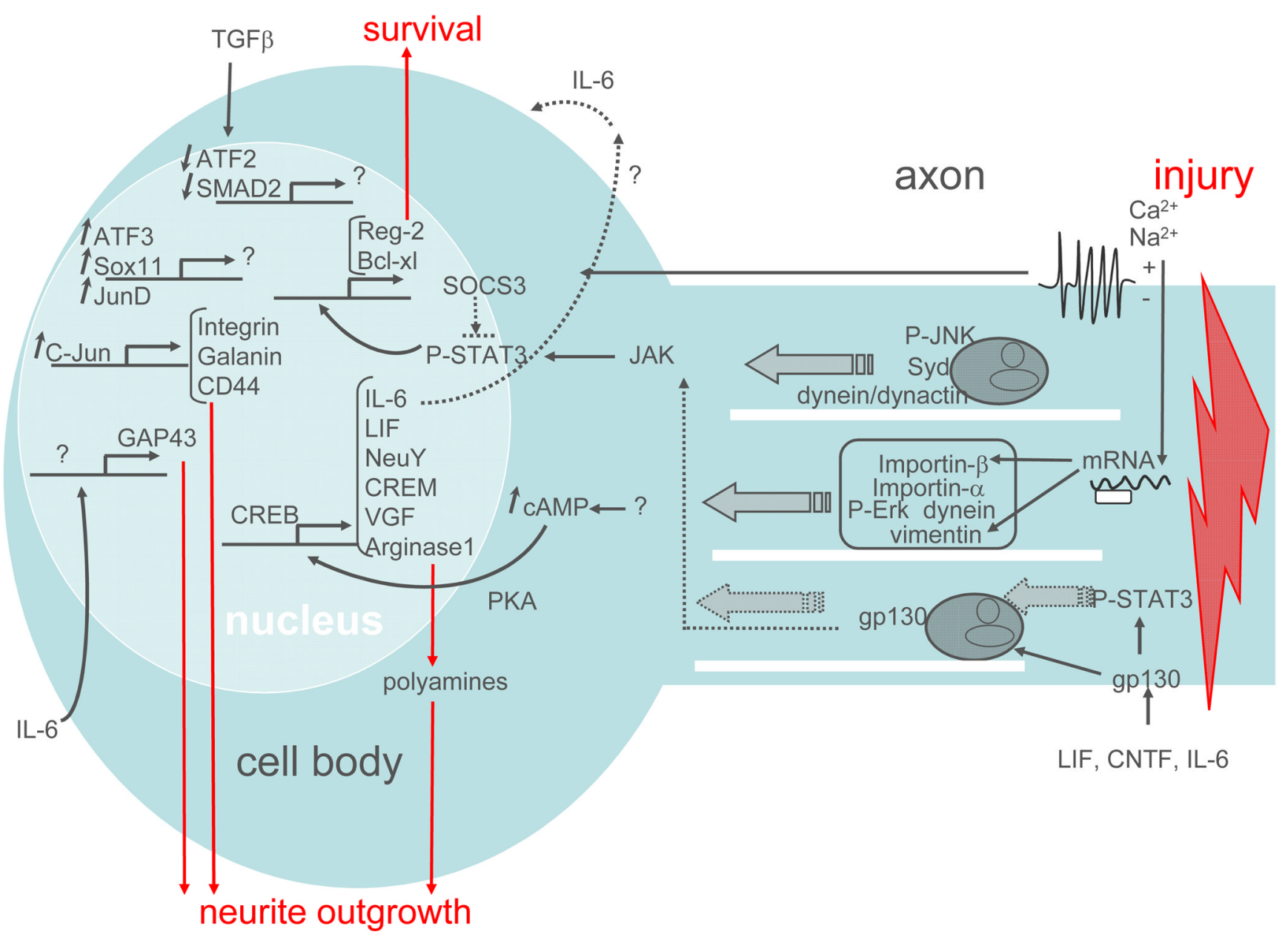

Figure 3. Activation of the intrinsic growth capacity by peripheral injury

Nerve injury triggers multiple signalling events in the axon, including membrane depolarization, JNK activation, mRNA translation, and cytokine-mediated STAT3 activation. These events lead to the microtubule-based retrograde transport of signaling molecules back to the cell body (shown by plain arrows). When these signalling molecules reach the cell body, they mediate the expression of a number of transcription factors that regulate the expression of genes involved in cell survival and neurite outgrowth. These downstream targets also include some components of the injury signal, such as IL-6 and LIF, which may amplify the injury signal via positive feedback. 